was found in 20 cases. Occasionally it was accompanied by pyrexia, and on two occasions by pains in the joints. There were also 2 cases with joint pains not accompanied by an erythema, and I case with pain over the lower third of the right femur.

Probably the most unusual case was that of a boy, 4 years of age, who received 2,000 units on the first day of illness. Eleven days later he had pyrexia, with slight cardiac irregularity, and a crop of whea!s developed on tise front of both legs, chiefly below the middle of the tibia. The wheals subsided, leaving round purplish hæmorrhagic stains, each about the size of a threepenny-piece. The stains gradually faded in two or three days.

1 REFERENCE.

1 Transactions of the Clinical Society of London, vol. xxxi.

\section{CERVELlO'S TREATMENT OF PHTHISIS.}

BY NEVELL E. NORWAY, M.R.C.E., L.R.C.P., Newquay.

A PRELIMINARY note on results obtained in England by the use of Cervello's " igazol," though it may seem somewhat premature, may be of interest to those who meditate giving it a trial. I saw the treatment being carried out under Professor Cervello's own direction at Palermo, and was not enthusiastic about it. A trial in three cases has, however, convinced me that it is a valuable aid to open-air treatment, especially where it is necessary to treat the patient at home, and in the following case it effected a result not possible in any other way:-

M. M., a girl telegraphist, age 25, unmarried, hip-joint disease twenty years, pulmonary tuberculosis ten years, large cavity below left clavicle sudden pyrexia, 10 $3^{\circ}$ mornings to $105^{\circ}$ in evenings, fine crepitations a over both litte liquid to cyaten beyond a dieine of an sort could be administered tas any thee days and o distressin of any sort duced distressing and clammy and she had apparently onjy a few hours to 1 , when, yielding to the wishes of the relatives, I allowed them to use a vaporiser. After it had burnt for two hours the patient slept for half an hour (the ing ceased forth with, temperature gradually fell to $100^{\circ}$, and in a week was normal in the mornings. Appetite came by degrees, and the patient invoriably slept when the vaporiser was used. It was used at first (on May $3 \mathrm{st}$ ) for two hours three times a day. At the end of three weeks the girl was out of doors as mucl as possible, and the vaporiser was only used twice a day.

On July 16th it was noticed that she had gained $6 \mathrm{lbs}$. in three weeks and very much more altogether. The temperature was now hardly ever $100^{\circ}$, the respirations were 18 . Crepitations had almost disappeared from the right side, and were much less in area on the left side. The cavity seemed more contracted on each examination. The girl was able to take a little outdoor exercise, and was in much the same health as before she suffered from acute miliary tuberculosis.

I have used "igazol" in two other cases, namely :

"B.," a schoolmaster, was picked up in the street with profuse hæmoptysis. Hammamelis, opium, and calomel were given to control hæmorrhage, but the chest condition was treated with "igazol." Gradual but steadv improvement has taken place. but an attempt to keep the patient out of doors all day has failed. as he feels that he must have the vaporiser at least twice a day to relieve his breathing and cough

"M. P." is not tuberculous, but I name the case to show that the treatment is a popular one with patients. and as illustrating the soothing effects of "igazol." The patient is gouty and asthmatical, with a laryngeal spasm which awakened him every night after about an hour's sleep. He is very tired of drugs. The use of the vaporiser for two hours each evening has greatly lessened cough and laryngeal spasm. The patient uses the vaporiser regularly, and expresses kimself as feeling better after doing so. The result is probably in this case due rather to the iodine than to the formalin, of which the "igazol" is composed.

This small experience is of no value in itself, except as confirming Professor Cèrvello's statements, but it has convinced me that "igazol" is a valuable aid to our methods of treating phthisis, and is a popular and agreeable remedy to patients.

Professor Th. Escherich has been elected Dean of the Medical Faculty of the University of Graz for the academic year 1900-1901.

Presentation.-Dr. Deeping, J.P., of Southend, was recently presented with a handsome silver epergne, a gold hunter watch, and an illuminated address. The inscription on the first-named was as follows: "Presented to G. D. Deeping, Esq., J.P., in appreciation of his many services to the town of Southend.on-Sea and as a token of their respect and esteem, by the residents, July 2 ist, 1900--F. F. Ramuz, Mayor."

\section{MEM ORANDA}

MEDICAL, SURGICAL, OBSTETRICAL, THERAPEUTICAL, PATHOLOGICAL, ETC.

\section{SPLINT FOR FRACTU RED HUMERUS.}

I HAVE found the splint shown in the accompanying diagram useful in cases of fracture of upper end of humerus. It is easily made from a flat piece of poroplastic felt of the shape here shown, and of a size suited to the patient. The dotted lines regulate the shape and size of the flaps that extend upwards round the joint, and mas be varied according to the requirements of the case. The body-piece should be securely
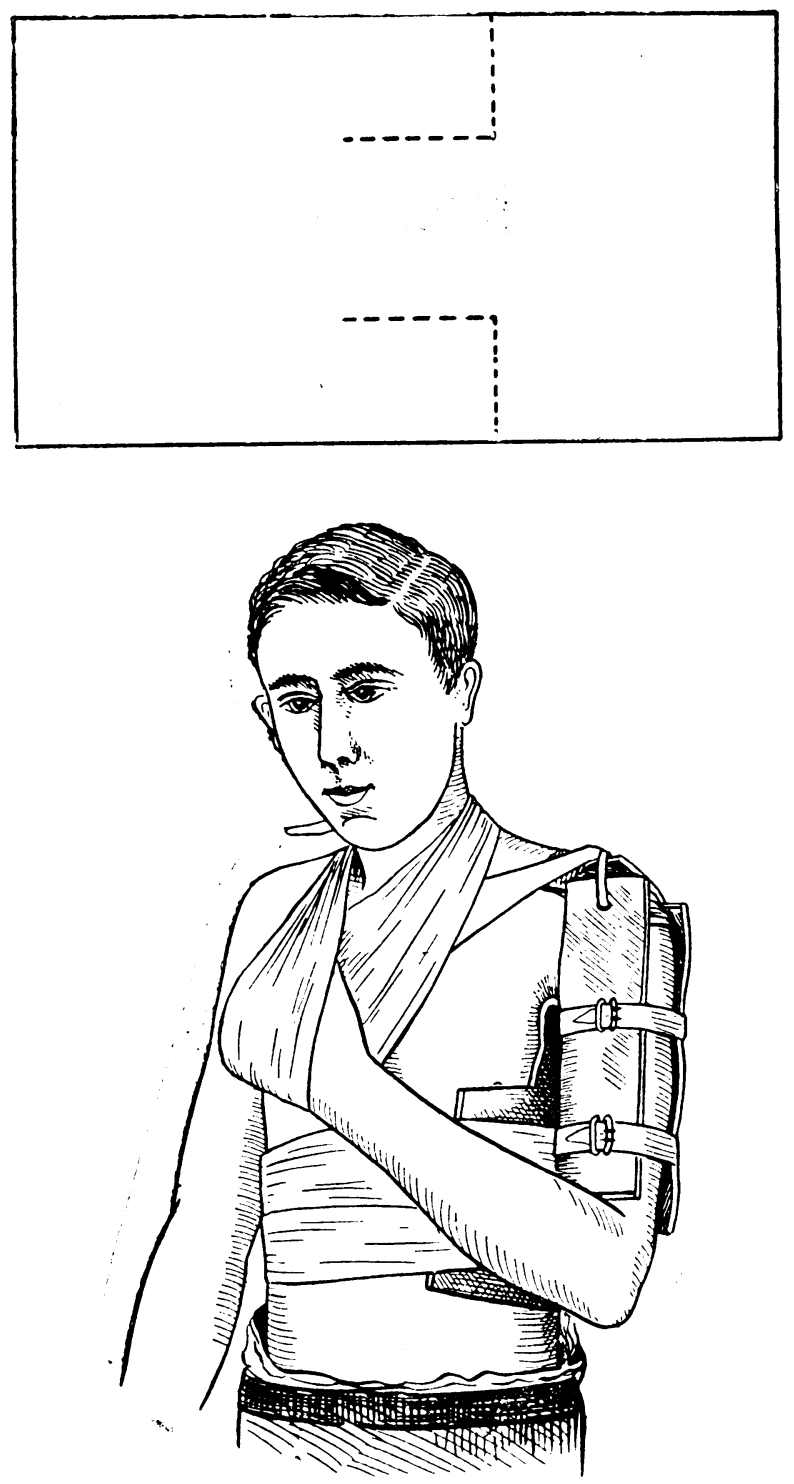

fixed to the tiunk by broad bands of stout plaster; and if great immobility of the arm is desired a band may be passed through holes made in the lower border of the arm-piece'and the adjoining body piece. It is my custom to mould the appliance in the tirst instance to the sound side; it then, when transferred, requires only a slight refitting. Dublin! 